\title{
Timing of Emergency Endoscopy for Acute Upper Gastrointestinal Bleeding: A Literature Review
}

\begin{abstract}
Fardad Ejtehadi ${ }^{1}$, Gholam Reza Sivandzadeh ${ }^{2, *}$, Ahmad Hormati ${ }^{3}$, Sajjad Ahmadpour ${ }^{4}$, Ramin Niknam ${ }^{5}$, Mahdi Pezeshki Modares ${ }^{3}$

1. Associate Professor of Medicine, Gastroentrohepatology Research Center, Namazi Hospital, Shiraz University of Medical Sciences, Shiraz, Iran

2. Assistant Professor of Medicine, Gatroenterohepatology Research Center, Shiraz University of Medical Sciences, Shiraz, Iran

3. Assistant professor of Gastroenterology, Gastrointestinal and Liver Diseases Research Center, Firozgar Hospital, Iran University

\section{ABSTRACT}

Upper gastrointestinal (GI) bleeding is a common cause for Emergency Department and hospital admissions and has significant mortality and morbidity if it remains untreated. Upper endoscopy is the key procedure for both diagnosis and treatment of acute upper GI bleeding. The aim of this article is to review the optimal timing of endoscopy in patients with acute upper GI bleeding. The cost-effectiveness and the influence of urgent or emergent endoscopy on patients' outcomes are discussed. Also, we compare and contrast the available evidence and guidelines regarding the recommended time points for performing endoscopy in different clinical settings.
\end{abstract} of Medical Sciences, Tehran, Iran

4. Assistant Professor of Radiopharmacy, Gastroenterology and Hepatology Diseases Research Center, Qom University of Medical Sciences, Qom, Iran

5. Associate Professor of Medicine, Gatroenterohepatology Research Center, Shiraz University of Medical Sciences, Shiraz, Iran

* Corresponding Author: Gholam Reza Sivandzadeh, MD Department of Internal Medicine, Gasteroenetrohepatology Research Center, Department of Internal Medicine, School of Medicine, Shiraz University of Medical Sciences, Namazi Hospital, Zand St., Shiraz, 7193711351, Fars, Iran.

Tel: + 987116473236

Fax: + 987116474316

Email: ghsivand@sums.ac.ir

Received: 17 Dec. 2020

Accepted: 02 Jun. 2021

\section{KEYWORDS:}

Gastrointestinal bleeding, Endoscopy timing, Diagnosis, Emergency medical care

Please cite this paper as:

Ejtehadi F, Sivandzadeh GR, Hormati A, Ahmadpour S, Niknam R, Pezeshki Modares M. Timing of Emergency Endoscopy for Acute Upper Gastrointestinal Bleeding: A Literature Review. Middle East J Dig Dis 2021;13:177-185. doi: 10.34172/mejdd.2021.223.

\section{INTRODUCTION}

Upper gastrointestinal (GI) bleeding is a common cause of Emergency Department referrals and hospital admissions, which has significant morbidity and mortality if it remains untreated. ${ }^{1-4}$ Acute massive GI bleeding incidence is about 40-150 episodes per 100,000 persons per year ${ }^{5-7}$ with $5-11 \%$ mortality rate ${ }^{8-11}$ and higher incidence and mortality rate among the elderly patients. ${ }^{12,13}$ The cost of overall upper GI bleeding is estimated to be more than 2 billion dollars in the United States annually .$^{14,15}$ Upper endoscopy is the procedure of choice for both diagnosis and treatment of acute upper GI bleeding and has a well known and established role in decreased mortality and re-bleeding. ${ }^{16-19}$ Although there have been many advances in the endoscopy techniques and development of modern devices, the mortality rate has not decreased significantly in recent decades. ${ }^{20,21}$ Most of the current guidelines and recommendations emphasize the role of early endoscopy (i.e. in the first 24 hours) and even during the first 16 hours as recommended by the Guidelines of the Romanian Society of Gastroenterology.22-25 Also, urgent endoscopy, as defined by the phrase "as soon as possible", is recommended for most of the severe, ongoing bleeding, hemodynamic instability, or in the patients with cirrhosis. ${ }^{24}$ However, in this setting, the optimal timing of endoscopy is necessary, and the cost-effectiveness and the influence of urgent or emergency endoscopy on patients' outcomes must be evaluated. 
Table 1: Pre and post endoscopy Rockall scoring system

\begin{tabular}{|c|c|c|c|c|}
\hline Variable & Score 0 & Score 1 & Score 2 & Score 3 \\
\hline Age & $<60$ & $60-79$ & $>80$ & \\
\hline Shock & No shock & $\begin{array}{c}\text { Pulse }>100 \\
\mathrm{BP}>100 \text { Systolic }\end{array}$ & $\mathrm{SBP}<100$ & $\begin{array}{c}\text { Renal failure, liver } \\
\text { failure, disseminated } \\
\text { malignancy }\end{array}$ \\
\hline Comorbidity & No major comorbidity & & $\begin{array}{l}\text { CHF, IHD any major } \\
\text { comorbidity }\end{array}$ & \\
\hline $\begin{array}{l}\text { Endoscopy } \\
\text { diagnosis }\end{array}$ & $\begin{array}{l}\text { Mallory-Weiss tear, no } \\
\text { lesion identified, and no } \\
\text { stigmata of recent bleeding }\end{array}$ & All other diagnoses & Malignancy of upper GI tract & \\
\hline $\begin{array}{l}\text { Evidence of recent } \\
\text { bleeding }\end{array}$ & None or dark spot only & & $\begin{array}{c}\text { Blood in upper GI tract, } \\
\text { adherent clot, visible or } \\
\text { spurting vessel }\end{array}$ & \\
\hline
\end{tabular}

Maximum additive score prior to diagnosis $=7$. Maximum additive score following diagnosis $=11$, Adapted from reference ${ }^{29}$

Abbreviations: $\mathrm{CHF}$, congestive heart failure; IHD, ischemic heart disease;

Also, local issues such as the availability of the resorts, equipment, intensive care unit (ICU) beds, active emergency operation rooms, and experienced gastroenterologist and nurses are among other concerns..$^{10,26,27}$

The aim of this study was to review the literature for performing endoscopy in the setting of acute upper GI bleeding and patient preparation that could be lifesaving, applicable, and cost-effective without imposing extra risk either to the patient or the equipment and the staff.

\section{Risk assessment}

Patients with upper GI bleeding may present with different symptoms such as coffee ground vomiting, hematochezia, melena, and fresh rectal bleeding. ${ }^{23}$ The source and cause of bleeding and clinical signs and symptoms are important predictors of mortality, morbidity, and chance of re-bleeding. ${ }^{28}$ In order to perform quantitative evaluation and risk assessment of the patients with GI bleeding, risk scoring systems have evolved and become more popular in recent years and are more often used to identify patients with increased risk of re-bleeding $(>5 \%)$ and mortality $(>1 \%) .^{29-31}$

The two most accepted and sensitive numerical scoring systems for GI bleeding risk assessment are the Glasgow-Blatchford Scoring system ${ }^{29}$ and the Rockall scoring system. ${ }^{31}$ Rockall scoring system, which was first introduced in 1996, is a mortality predictor scoring system that estimates the risk of re-bleeding too. ${ }^{32,33}$ The test can be applied both prior to endoscopy (Clinical Rockall score) and after endoscopy (Full Rockall scoring) (Table 1). Rockall scoring system with a pre-endoscopy score of " 0 " identifies patients at very low risk of re-bleeding or death. With this score, it may even be possible to discharge the patients to perform outpatient (OPD) endoscopy as soon as possible. Patients with a full (including the endoscopic findings) Rockall score of $<3$ have a low risk of re-bleeding or death and can be considered for early discharge. ${ }^{33,34}$

The Glasgow-Blatchford Scoring system predicts poor outcomes and the need for endoscopy in patients with non-variceal GI bleeding based on the clinical and laboratory parameters without the need for endoscopy ${ }^{32,35}$ (Table 2). The score includes pulse, systolic blood pressure, hemoglobin, and blood urea level, presence of syncope or melena, and evidence or history of heart failure or liver disease. ${ }^{29,36-38} \mathrm{~Pa}$ tients with a score of " 0 " are considered as low risk and have the least need for endoscopy, surgery, or transfusion. However, any other patients with scores of more than " 0 " are considered high-risk patients. Patients with a score of " 0 " could be considered for OPD early endoscopy. ${ }^{29,39}$ It is important to state that the cutoff value of score " 0 " has both a sensitivity and specificity of $100 \%$ to predict the need for treatment in acute upper GI bleeding with a negative predictive value of $100 \% .^{28}$ The sensitivity for the cutoff value of 2 or less still remains $100 \%,{ }^{28}$ while the negative predictive value decreases to $98.1 \%{ }^{35}$ 
Table 2: Glasgow-Blatchford Scoring system

\begin{tabular}{|c|c|}
\hline \multicolumn{2}{|l|}{ Glasgow-Blatchford Score } \\
\hline Admission risk factor & Score \\
\hline \multicolumn{2}{|l|}{ BUN (mg/dL) } \\
\hline$<6.5$ & 0 \\
\hline$\geq 6.5<8 \cdot 0$ & 2 \\
\hline$\geq 8 \cdot 0<10 \cdot 0$ & 3 \\
\hline$\geq 10 \cdot 0<25 \cdot 0$ & 4 \\
\hline$\geq 25$ & 6 \\
\hline \multicolumn{2}{|l|}{ Hemoglobin (g/L) for men } \\
\hline$\geq 13.0$ & 0 \\
\hline$\geq 12.0<13.0$ & 1 \\
\hline$\geq 10.0<12.0$ & 3 \\
\hline$<10.0$ & 6 \\
\hline \multicolumn{2}{|c|}{ Systolic blood pressure (mm Hg) } \\
\hline$\geq 100$ & 0 \\
\hline $100-109$ & 1 \\
\hline $90-99$ & 2 \\
\hline$<90$ & 3 \\
\hline \multicolumn{2}{|l|}{ Other Factors } \\
\hline Pulse $\geq 100$ (per min) & 1 \\
\hline Presentation with melena & 1 \\
\hline Presentation with syncope & 2 \\
\hline Hepatic disease & 2 \\
\hline Cardiac failure & 2 \\
\hline
\end{tabular}

Both systems are very well applicable and sensitive ,${ }^{40}$ however, the sensitivity and the accuracy of the Glasgow-Blatchford Scoring system has been reported to be higher in some recent studies, ${ }^{33,41,42}$ and it is regarded as the most accurate scoring system for assessment of patients with upper GI bleeding and predicting the need for endoscopy and 30-day mortality rate. $^{41}$

\section{Time to endoscopy \& literature review}

The National Institute for Health and Care Excellence (NICE) guideline recommendations include risk assessment by Glasgow-Blatchford Score and Full Rockall score (after endoscopy) with early endoscopy (during the first 24 hours) for all patients, and immediate endoscopy for the patients with severe acute GI bleeding after resuscitation. ${ }^{4,40}$

The Scottish guideline for GI bleeding recommends hospital admission and early endos- copy for the patients at the age of 60 , witnessed hematemesis and hematochezia, liver disease, or known varices and hemodynamic disturbance (systolic blood pressure (SBP) $<100 \mathrm{~mm} \mathrm{Hg}$ and pulse rate $>$ beats 100/min) ${ }^{25}$ International Consensus Recommendations on the Management of Patients with Non-variceal Upper Gastrointestinal Bleeding recommends that early endoscopy (in the first 24 hours of presentation) for most patients with upper GI bleeding. ${ }^{42,43}$ Guidelines of the American Society of Gastrointestinal Endoscopy (ASGE) recommends early endoscopy (within the first 24 hours of presentation) after risk stratification, both variceal and non-variceal upper GI bleeding. ${ }^{44,45}$

While almost all guidelines support the early endoscopy with the definition of "within the first 24 hours of presentation", the effectiveness, risks, and cost-benefit effect of performing the endoscopy in a shorter interval must be evaluated. ${ }^{23,26,40,42,44,46}$ The time interval for "early endoscopy" varies from 2 to maximum 24 hours after initial presentation . ${ }^{23,24}$ 47-49 The terms of "urgent", "emergency", and "very early" endoscopy have been used interchangeably with different time interval definitions in the literature, and urgent (or as soon as possible) endoscopy definition varies from arrival time to 6 hours after initial presentation. ${ }^{24,26,42}$

One retrospective study on 500 patients with non-variceal upper GI bleeding from 2004 to 2006 showed that endoscopy within 6 hours compared with 6-24 hours was not associated with a different mortality rate, need for blood transfusion, and surgery. ${ }^{26}$ A study on 169 patients with acute non-variceal GI bleeding that had either systolic blood pressure less than $100 \mathrm{~mm} \mathrm{Hg}$ or pulse rate more than 100 beats per minute showed no significant difference in adverse outcomes or transfusion requirements in patients receiving endoscopy in the first 6 hours compared with the first 6-24 hours. ${ }^{50}$ Another meta-analysis with 528 patients showed no significant difference in mortality (OR; 0.70 [CI; 0.14 to 3.57$]$ ), surgery (OR; 1.16 [CI; 0.39 to 3.51$])$, or re-bleeding (OR; $0.71[\mathrm{CI}$; 0.28 to 1.81$]$ ) among the high risk patients who had undergone endoscopy in the first 12 hours compared with 12-24 hours after initial presentation. ${ }^{42}$ 
One study on 689 high-risk patients found no significant difference in the mortality rate among the patients who had undergone endoscopy within 3 hours after presentation compared with 3-24 hours $(p=0.67451) .{ }^{24}$

Some retrospective analyses comparing urgent endoscopy (within first 8 hours) versus early endoscopy (8-24 hours) found no difference in clinical outcomes. ${ }^{42}$ Interestingly, one study on 6.749 patients in the U.K found no difference between the mortality of the patients with GI bleeding who were admitted on the weekend vs. weekday $(\mathrm{OR}=0.93$; $[95 \% \mathrm{CI}$; $0.75-1.16),{ }^{51}$ but another similar study in the U.S. on 391,119 patients found a higher rate in-hospital mortality among patients that had been admitted on weekends $(\mathrm{OR}=1.21$; [95\% CI, $1.09-1.35]))^{52}$ In contrast to the above findings, some different results have been reported in the literature, as well. One study found that the presence of fresh blood in nasogastric tubes, hemoglobin level less than $8 \mathrm{~g} /$ $\mathrm{dL}$, hemodynamic instability, and WBC count more than $12000 / \mathrm{mcL}$ are independent predictors of active bleeding and the need for the endoscopy to be performed within the first 12 hours of the initial presentation $(p<$ 0.050). ${ }^{53}$ A study by Lim and colleagues ${ }^{54}$ on 394 high-risk upper GI bleeding revealed that the allcause in-hospital mortality was significantly lower in the group of patients who had an endoscopy done within the first 13 hours of presentation compared with the other group that had undergone endoscopy in $13-24 \mathrm{~h}(0 \%$ vs. $44 \% ; p<0.001)$.

NICE guidelines on acute upper GI bleeding recommend performing endoscopy immediately in unstable patients with severe acute upper GI bleeding immediately after resuscitation. ${ }^{40,43}$ American Association for the Study of Liver Disease (AASLD) practical guidelines on prevention and management of gastroesophageal varices and variceal hemorrhage in cirrhosis recommend that endoscopy should be done within the 12 hours of presentation to diagnose and treat variceal bleeding (Class I, Level A). ${ }^{55}$ One study on 210 patients with acute variceal bleeding and stable hemodynamic parameters found no significant association between time to endoscopy and mortality $(\mathrm{OR}=1.0$ [95\% CI; 0.92-1.08], $p=$
$0.91),{ }^{56}$ while another retrospective analysis on 311 consecutive acute variceal bleeding cases found that delayed endoscopy (more than 15 hours after presentation) was an independent risk factor for mortality $\left(\mathrm{OR}=3.67[95 \% \mathrm{CI} ; 1.27-10.39) .{ }^{57}\right.$

\section{DISCUSSION}

Acute upper GI bleeding as a major life-threatening condition is one of the most common medical emergencies. It costs billions of dollars annually and estimated a crude overall in-hospital mortality of $10 \% .^{58,59}$

Endoscopy not only can offer identification of the source of bleeding but also can be used in the hemostatic treatment of lesions with active bleeding. This type of treatment can stop bleeding in patients with high-risk lesions and can reduce the need for surgery, as well. It is proposed that endoscopic hemostatic treatment can reduce further bleeding in high-risk lesions. ${ }^{60} \mathrm{It}$ is recommended that endoscopy was performed within 24 hours after the presentation for patients with acute upper GI bleeding. ${ }^{61}$ Various study findings have demonstrated that urgent endoscopy (the definitions of which have varied among studies, ranging from within 2 hours to within 12 hours after presentation) in unselected patients with acute upper GI bleeding did not decrease mortality. ${ }^{62,63}$

In recent years, many improvements have been made to endoscopic devices. New technology and more sophisticated instruments allow us to perform advanced diagnosis and therapeutic procedures in the management of GI bleeding. However, despite improvements in endoscopic devices and associated modalities, the mortality rate has not changed in the past decade and has been reported to range between $6 \%$ and $12 \%{ }^{64-66}$ Therefore, emphasizing the need for improvement in this area is worthy. Some studies have reported that mortality was unchanged for the past 50 years. ${ }^{59}$ In order to improve patients' care, authors believe it is now time to focus on other aspects of management as well as the technical aspects. The importance of "risk assessment" and "time to endoscopy" in the management of GI bleeding is well evident. Therefore, the authors decided to review the current guidelines and recommendations with a focus on risk assessment and time to endoscopy 
for the management of acute upper GI bleeding.

It is recommended that patients with acute upper GI bleeding undergo endoscopy within 24 hours; however, for the time range shorter than 24 hours, it has not been adequately explained. In one study, James and colleagues assigned patients with overt signs of acute upper GI bleeding and a GlasgowBlatchford score of 12 or higher (scores range from 0 to 23 , with higher scores indicating a higher risk of further bleeding or death) to undergo endoscopy within 6 hours (urgent-endoscopy group) or between 6 and 24 hours (early-endoscopy group). Findings revealed that among 516 patients who were enrolled in the study, the 30-day mortality was $8.9 \%$ (23 of 258 patients) in the urgent-endoscopy group and $6.6 \%$ (17 of 258) in the early-endoscopy group (difference, 2.3 percentage points; 95\% CI, -2.3 to 6.9). Findings revealed further bleeding within 30 days in 28 patients $(10.9 \%)$ in the urgent endoscopy group and in $20(7.8 \%)$ in the early-endoscopy group (difference, 3.1 percentage points; 95\% CI, -1.9 to 8.1). When initial endoscopy was performed, ulcers with active bleeding or visible vessels were seen in 105 out of the 158 patients $(66.4 \%)$ with peptic ulcers in the urgent-endoscopy group, and 76 of 159 $(47.8 \%)$ in the early endoscopy group, as well. After the initial endoscopy, 155 patients $(60.1 \%)$ in the urgent-endoscopy group and 125 (48.4\%) in the earlyendoscopy group underwent endoscopic hemostatic treatment. ${ }^{67}$ This study revealed that for patients with acute GI bleeding who were predicted to be at high risk for further bleeding or death, endoscopy was performed within 6 hours after gastroenterology consultation. This medical evaluation that used the Glasgow-Blatchford Score as a measure of risk would forestall further bleeding and improve outcomes as compared with endoscopy performed between 6 and 24 hours after consultation.

Abougergi and co-workers performed a longitudinal study of upper GI hemorrhage (UGIH) hospitalizations by using the nationwide inpatient sample. ${ }^{59}$ They found that the non-variceal UGIH mortality rate decreased from $4.5 \%$ in 1989 to $2.1 \%$ in 2009 . Also, the findings of the study revealed that non-variceal UGIH incidence decreased from 108 to 78 cases/100,000 persons in 1994 and 2009, respectively. It is reported that in-hospital upper endoscopy and endoscopic therapy rates increased from $70 \%$ and $10 \%$ in 1989 to $85 \%$ and $27 \%$ in 2009 , respectively, and the early endoscopy rate increased from $36 \%$ in 1989 to $54 \%$ in 2009, as well. Although the median length of hospitalization decreased from 4.5 days in 1989 to 2.8 days in 2009 , the median total hospitalization charges increased from $\$ 9249$ in 1989 to $\$ 20.370$ in 2009 .

After an initial presentation of GI bleeding, risk stratification by either the Rockall scoring system or Glasgow-Blatchford Scoring system must be done. Glasgow-Blatchford Scoring system seems to be more applicable at the patient bedside, endoscopy independent, and was reported to be more accurate and sensitive. Patients with no history of melena, syncope, cardiac failure, and hepatic disease who have pulse rate $<100$ beats per minute, systolic blood pressure $\geq 100 \mathrm{~mm} \mathrm{Hg}$, hemoglobin level $\geq$ $13.0 \mathrm{~g} / \mathrm{L}$ for men or $\geq 12.0 \mathrm{~g} / \mathrm{L}$ for women, and BUN level $<6.5 \mathrm{mg} / \mathrm{dL}$, have Glasgow-Blatchford Score of " 0 " and are categorized as low-risk patients. This group of patients could be considered for OPD early endoscopy with $100 \%$ sensitivity, specificity, and negative predictive value. Other patients must be considered as high risk and should be scheduled for early endoscopy in less than 24 hours of the initial presentation. In an international multicenter prospective study involving 3012 patients, a threshold score of 7 or higher was shown to provide the most accurate prediction of whether a patient will be determined to need endoscopic treatment. Findings revealed that the Glasgow Blatchford Score had high accuracy in predicting the need for hospital-based intervention or death. Scores of $\leq 1$ appear the optimum threshold for directing patients to outpatient management. The area under the receiver operating characteristic curve of scores (AUROCs) for the other endpoints is less than 0.80 ; therefore their clinical utility for these outcomes seems to be limited. ${ }^{68}$

All patients who do not meet the above criteria are considered "high-risk patients". Early endoscopy (within the first 24 hours of initial presentation) must be done for them. Most of the current evidence does not 
show any significant effect of performing endoscopy in a shorter interval on mortality and outcome of the patients with non-variceal upper GI bleeding. However, two studies found a beneficial effect on mortality if the endoscopy is done in the first 12 hours after presentation. So the decision for the time of endoscopy within the first 24 hours should be made for each patient separately.

It is recommended that endoscopy be done immediately after resuscitation for severe acute upper GI bleeding. All patients with cirrhosis, history of liver disease, or at risk of variceal bleeding should have an endoscopy in the first 12 hours after each type of upper GI bleeding presentation. Finally, it must be emphasized that the two most common causes of upper GI bleeding are peptic ulcer disease and variceal bleeding. Hence, any recommendation should cover these underlying pathologies. Patients suspected of upper GI bleeding should be assessed carefully in an acute clinical setting. Despite some minor differences, all of the above guidelines and recommendations could be used as valuable tools to safely and accurately assess patients. Available logistics and individual circumstances should be considered in decision-making and management plans. More investigations and data from the large multicenter registries will be helpful in detecting the best time for endoscopy in the first 24 hours in the future.

\section{CONCLUSION}

It must be emphasized that the two most common causes of upper GI bleeding are peptic ulcer disease and variceal bleeding. Patients suspected of upper GI bleeding in an acute clinical setting should be assessed carefully and resuscitated well. Taken together, despite some minor differences, all of the above guidelines and recommendations could be used as valuable tools to safely and accurately assess the patients. Available logistics and individual circumstances should be considered in decisionmaking and management plans. The majority of related studies in this field were relatively small, single-center, and mainly reflected GI bleeding incidence and treatment outcomes at tertiary-care centers that must be covered in future studies. More investigations and data from the large multicentre registries will be helpful in the timely performing of endoscopy procedures.

\section{Author contributions:}

Fardad Ejtehadi, Gholam Reza Sivandzadeh, and Ramin Niknam contributed to idea generation, draft preparation, literature review, and preparing the manuscript equally. Ahmad Hormati, and Sajjad Ahmadpour, contributed to the literature review and preparing the manuscript.

\section{ETHICAL APPROVAL}

There is nothing to be declared.

\section{CONFLICT OF INTEREST}

The authors declare no conflict of interest related to this work.

\section{REFERENCES}

1. Lau JY, Barkun A, Fan DM, Kuipers EJ, Yang YS, Chan FK. 1 Challenges in the management of acute peptic ulcer bleeding. Lancet 2013;381:2033-43. doi: 10.1016/S01406736(13)60596-6.

2. Wang J, Bao YX, Bai M, Zhang YG, Xu WD, Qi XS. Restrictive vs liberal transfusion for upper gastrointestinal bleeding: a meta-analysis of randomized controlled trials. W J Gastroenterol 2013;19:6919-27. doi: 10.3748/wjg. v19.i40.6919.

3. Khamaysi I, Gralnek IM. Acute upper gastrointestinal bleeding (UGIB) - initial evaluation and management. Best Pract Res Clin Gastroenterol 2013;27:633-8. doi: 10.1016/j.bpg.2013.09.002. Epub Sep 25.

4. Ghomi SYF, Shakeri M, Hoseinpor Z, Mohammadbeigi A. Blatchford and Rockall Systems in the Prediction of Upper Gastrointestinal Bleeding. Govaresh 2019;24:88-94.

5. Vreeburg EM, Snel P Fau - de Bruijne JW, de Bruijne Jw Fau - Bartelsman JF, Bartelsman Jf Fau - Rauws EA, Rauws Ea Fau Tytgat GN, Tytgat GN. 4 Acute upper gastrointestinal bleeding in the Amsterdam area: incidence, diagnosis, and clinical outcome. Am J Gastroenterol 1997;92:236-43.

6. British Society of Gastroenterology Endoscopy Committee. Nonvariceal upper gastrointestinal haemorrhage. Gut 2002;51:iv1iv6. doi: 10.1136/gut.51.suppl_4.iv1.

7. Rockall TA, Logan RFA, Devlin HB, Northfield TC. Incidence of and mortality from acute upper gastrointestinal haemorrhage in the United Kingdom. BMJ 1995;311:222-6. doi: 10.1136/ bmj.311.6999.222.

8. Wilcox CM, Clark WS. Causes and outcome of upper and lower 
gastrointestinal bleeding: the Grady Hospital experience. South Med J 1999;92:44-50. doi: 10.1097/00007611-19990100000008.

9. Yavorski RT, Wong Rk Fau - Maydonovitch C, Maydonovitch C Fau - Battin LS, Battin Ls Fau - Furnia A, Furnia A Fau Amundson DE, Amundson DE. Analysis of 3,294 cases of upper gastrointestinal bleeding in military medical facilities. $\mathrm{Am} \mathrm{J}$ Gastroenterol 1995;90:568-73.

10. Tai CM, Huang SP, Wang PHP, Lee TC, Chang CY, Tu $\mathrm{CH}$, et al. High-risk ED patients with non-variceal upper gastrointestinal hemorrhage undergoing emergency or urgent endoscopy: a retrospective analysis. Am J Emerg Med 2007;25:273-8. doi: 10.1016/j.ajem.2006.07.014.

11. Palmer K. Acute upper gastrointestinal haemorrhage. $\mathrm{Br}$ Med Bull 2007;83:307-24. doi: 10.1093/bmb/ldm023.

12. Czernichow P, Hochain P, Nousbaum JB, Raymond JM, Rudelli A, Dupas JL, et al. Epidemiology and course of acute upper gastro-intestinal haemorrhage in four French geographical areas. Eur J Gastroenterol Hepatol 2000;12:175-81. doi: 10.1097/00042737-20001202000007.

13. Manning-Dimmitt LL, Dimmitt SG, Wilson GR. Diagnosis of Gastrointestinal Bleeding in Adults. Am Fam Physician 2005:71:1339-46.

14. Gilbert DA. Epidemiology of upper gastrointestinal bleeding. Gastrointest Endosc 1990;36:S8-13.

15. Johanson JF. Curbing the costs of GI bleeding. Am J Gastroenterol 1998;93:1384-5. doi: 10.1111/j.15720241.1998.01384.x.

16. Jutabha R, Jensen DM. Management of upper gastrointestinal bleeding in the patient with chronic liver disease. Med Clin North Am 1996;80:1035-68. doi: 10.1016/s0025-7125(05)70479-x.

17. Adang RP, Vismans JF, Talmon JL, Hasman A, Ambergen AW, Stockbrügger RW. Appropriateness of indications for diagnostic upper gastrointestinal endoscopy: association with relevant endoscopic disease. Gastrointest Endosc 1995;42:390-7.

18. Cook DJ, Guyatt GH, Salena BJ, Laine LA. Endoscopic therapy for acute non-variceal upper gastrointestinal hemorrhage: a metaanalysis. Gastroenterology 1992;102:139-48. doi: 10.1016/00165085(92)91793-4.

19. Hormati A, Mohammadbeigi A, Mousavi SM, Saeidi M, Shafiee H, Aminnejad R. Anesthesia related complications of gastrointestinal endoscopies; a retrospective descriptive study. Middle East J Dig Dis 2019;11:147. doi: 10.15171/ mejdd.2019.141.

20. Cappell MS, Friedel D. Acute non-variceal upper gastrointestinal bleeding: Endoscopic diagnosis and therapy. Med Clin N Am 2008;92:511-50. doi: 10.1016/j.mcna.2008.01.001.

21. Longstreth GF, Feitelberg SP. Hospital care of acute nonvariceal upper gastrointestinal bleeding: 1991 versus 1981. $J$ Clin Gastroenterol 1995;19:189-93. doi: 10.1097/00004836199410000-00003.

22. Arasaradnam RP, Donnelly MT. Acute endoscopic intervention in non-variceal upper gastrointestinal bleeding. Postgrad Med J 2005;81:92-8. doi: 10.1136/pgmj.2004.020867.

23. Holster IL. Management of acute non-variceal upper gastrointestinal bleeding: Current policies and future perspectives. World J Gastroenterol 2012;18:1202. doi: 10.3748/wjg.v18. i11.1202.

24. Boţianu AM, Matei D, Tanţău M, Acalovschi M. Urgent versus Early Endoscopy in High Risk Patients with Acute Upper Gastrointestinal Bleeding: a Comparative Study in a Tertiary Center with a Permanent Endoscopy Call. Rom J Intern Med 2013;51:35-40.

25. Scotish Intercollegiate Guidelines Network(SIGN), Management of acute upper and lower gastrointestinal bleeding. 2008;Septamber.

26. Sarin N, Monga N, Adams PC. Time to endoscopy and outcome in upper gastrointestinal bleeding. Can J Gastroenterol 2009;23:489-93. doi: 10.1155/2009/604639.

27. Kelvin KF. Tsoi, Ma TKW, Sung JJY. Endoscopy for upper gastrointestinal bleeding: how urgent is it? Nat Rev Gastroenterol Hepatol 2009;6:463-9. doi: 10.1038/nrgastro.2009.108.

28. Jansen L, Leffers P, Hermans M, Stassen P, Masclee A, Keulemans Y. Identification of patients with upper gastrointestinal bleeding who do not need immediate treatment. Neth JMed 2011;69:384-8.

29. Blatchford O, Murray WR, Blatchford M. A risk score to predict need for treatment for uppergastrointestinal haemorrhage. Lancet 2000;356:1318-21. doi: 10.1016/S0140-6736(00)02816-6.

30. Ch'ng CL, Kingham JG. Scoring systems and risk assessment for upper gastrointestinal bleeding. Eur J Gastroenterol Hepatol 2001;13:1137-9. doi: 10.1097/00042737-200110000-00002.

31. Rockal TA, Logan RF, Devlin HB, Northfield TC. Risk assessment after acute upper gastrointestinal haemorrhage. Gut 1996;38:316-21. doi: 10.1136/gut.38.3.316.

32. Romagnuolo J, Barkun AN, Robert Enns, Armstrong D, Gregor J. Simple clinical predictors may obviate urgent endoscopy in selected patients with non-variceal upper gastrointestinal tract bleeding. Arch Intern Med 2007;167:265-70. doi: 10.1001/ archinte.167.3.265.

33. Sanders D, Carter M, Goodchap R, Cross S, Gleeson D, Lobo A. Prospective validation of the Rockall risk scoring system for upper GI hemorrhage in subgroups of patients with varices and peptic ulcers. Am J Gastroenterol 2002;97:630-5. doi: 10.1111/j.1572-0241.2002.05541.x.

34. Chen IC, Hung MS, Chiu TF, Chen JC, Hsiao CT. Risk scoring systems to predict need for clinical intervention for patients with non-variceal upper gastrointestinal tract bleeding. Am J Emerg Med 2007;25:774-9. doi: 10.1016/j.ajem.2006.12.024.

35. Schiefer M, Aquarius M, Leffers P, Stassen P, van Deursen C, Oostenbrug L, et al. Predictive validity of the Glasgow Blatchford Bleeding Score in an unselected emergency department population in continental Europe. Eur J Gastroenterol Hepatol 2012;24:382-7. doi: 10.1097/MEG.0b013e3283505965.

36. Masaoka T, Suzuki H, Hori S, Aikawa N, Hibi T. Blatchford 
scoring system is a useful scoring system for detecting patients with upper gastrointestinal bleeding who do not need endoscopic intervention. $J$ Gastroenterol Hepatol 2007;22:1404-8. doi: 10.1111/j.1440-1746.2006.04762.x.

37. Robins GG, Sarwar MS, Armstrong MJ, Denyer ME, Bush S, Hassan T, et al. Evaluation of the need for endoscopy to identify low-risk patients presenting with an acute upper gastrointestinal bleed suitable for early discharge. Postgrad Med J 2007;83:76872. doi: 10.1136/pgmj.2007.061614.

38. Stanley AJ, Ashley D, Dalton HR, Mowat C, Gaya DR, Thompson E, et al. Outpatient management of patients with low-risk upper-gastrointestinal haemorrhage: multicentre validation and prospective evaluation. Lancet 2009;373:42-7. doi: 10.1016/ S0140-6736(08)61769-9.

39. Atkinson RJ, Hurlstone DP. Usefulness of prognostic indices in upper gastrointestinal bleeding. Best Pract Res Clin Gastroenterol 2008;22:233-42. doi: 10.1016/j.bpg.2007.11.004.

40. Dworzynski K, Pollit V, Kelsey A, Higgins B, Palmer K, Guideline Development Group. Management of acute upper gastrointestinal bleeding: summary of NICE guidance. $B M J$ 2012;344:e3412. doi: 10.1136/bmj.e3412.

41. Laursen SB, Hansen JM, Muckadell OBSD. The Glasgow Blatchford Score Is the Most Accurate Assessment of Patients With Upper Gastrointestinal Hemorrhage. Clin Gastroenterol Hepatol 2012;10:1130-5. doi: 10.1016/j.cgh.2012.06.022.

42. Barkun AN, Bardou M, Kuipers EJ, Sung J, Hunt RH, Martel $\mathrm{M}$, et al. International Consensus Recommendations on the Management of Patients With Nonvariceal Upper Gastrointestinal Bleeding. Ann Intern Med 2010;152:101-13. doi: 10.7326/0003-4819-152-2-201001190-00009.

43. Hormati A, Zamani F, Mohaddes M, Saeidi M, Alemi F. An Unusual Treatment for Massive and Refractory Bleeding after Endoscopic Retrograde Cholangiopancreatography. Middle East J Dig Dis 2019;11:116-8. doi: 10.15171/mejdd. 2018.137.

44. Hwang JH, Fisher D A, Ben-Menachem T, Chandrasekhara V, Chathadi K, Anton Decker C, et al .The role of endoscopy in the management of acute non-variceal upper GI bleeding. Gastrointest Endosc 2012;75:1132-8. doi: 10.1016/j.gie.2012.02.033.

45. Qureshi W, Adler DG, Davila R, Egan J, Hirota W, Leighton J, et al. ASGE Guideline: the role of endoscopy in the management of variceal hemorrhage, updated July 2005. Gastrointest Endosc 2005;62:651-5. doi: 10.1016/j.gie.2005.07.031.

46. ASGE Standards of Practice Committee; Banerjee S, Cash BD, Dominitz JA, Baron TH, Anderson MA, et al. The role of endoscopy in the management of patients with peptic ulcer disease. Gastrointest Endosc 2010;71:663-8. doi: 10.1016/j. gie.2009.11.026.

47. Bjorkman DJ, Zaman A, Fennerty MB, Lieberman D, Disario JA, Guest-Warnick G. Urgent vs. elective endoscopy for acute non-variceal upper-GI bleeding: an effectiveness study. Gastrointest Endosc 2004;60:1-8. doi: 10.1016/s0016-5107(04)01287-8.

48. Lee JG, Turnipseed S, Romano PS, Vigil H, Azari R, Melnikoff N, et al. Endoscopy-based triage significantly reduces hospitalization rates and costs of treating upper GI bleeding: a randomized controlled trial. Gastrointest Endosc 1999;50:755-61. doi: 10.1016/s0016-5107(99)70154-9.

49. Spiegel BMR, Vakil NB, Ofman JJ. Endoscopy for acute nonvariceal upper gastrointestinal tarct hemorrhage.is sooner the better. Arch Intern Med 2001;161:1393-404. doi: 10.1001/ archinte.161.11.1393.

50. Targownik LE, Murthy S, Keyvani L, Leeson S. The role of rapid endoscopy for high-risk patients with acute non-variceal upper gastrointestinal bleeding. Can J Gastroenterol 2007;21:425-9. doi: 10.1155/2007/636032.

51. Jairath V, Kahan BC, Logan RF, Hearnshaw SA, Travis SP, Murphy MF, et al. Mortality from acute upper gastrointestinal bleeding in the United kingdom: does it display a "weekend effect"? Am J Gastroenterol 2011;106:1621-8. doi: 10.1038/ ajg.2011.172.

52. Ananthakrishnan AN, McGinley EL, Saeian K. Outcomes of weekend admissions for upper gastrointestinal hemorrhage: a nationwide analysis. Clin Gastroenterol Hepatol 2009;7:296302e1. doi: 10.1016/j.cgh.2008.08.013.

53. Adamopoulos A, Baibas N, Efstathiou S, Tsioulos D, AG AM, AATsami. Differentiation between patients with acute upper gastrointestinal bleeding who need early urgent upper gastrointestinal endoscopy and those who do not. A prospective study. Eur J Gastroenterol Hepatol 2003;15:381-7. doi: 10.1097/00042737200304000-00008.

54. Lim LG, Ho KY, Chan YH, Teoh PL, Khor CJ, Lim LL, et al. Urgent endoscopy is associated with lower mortality in high-risk but not low-risk non-variceal upper gastrointestinal bleeding. Endoscopy 2011;43:300-6. doi: 10.1055/s-0030-1256110.

55. Garcia-Tsao G, Sanyal AJ, Grace ND, Carey W. Prevention and management of gastroesophageal varices and variceal hemorrhage in cirrhosis. Hepatology 2007;46:922-38. doi: 10.1002/ hep. 21907.

56. Cheung J, Soo I, Bastiampillai R, Zhu Q, Ma M. Urgent vs. non-urgent endoscopy in stable acute variceal bleeding. Am J Gastroenterol 2009;104:1125-9. doi: 10.1038/ajg.2009.78.

57. Hsu YC, Chung CS, Wang HP. Application of endoscopy in improving survival of cirrhotic patients with acute variceal hemorrhage. Int $J$ Hepatol 2011;2011:893973. doi: 10.4061/2011/893973.

58. Hearnshaw SA, Logan RF, Lowe D, Travis SP, Murphy MF, Palmer KR. Acute upper gastrointestinal bleeding in the UK: patient characteristics, diagnoses and outcomes in the 2007 UK audit. Gut 2011;60:1327-35. doi: 10.1136/gut.2010.228437.

59. Abougergi MS, Travis AC, Saltzman JR. The in-hospital mortality rate for upper GI hemorrhage has decreased over 2 decades in the United States: a nationwide analysis. Gastrointest Endosc 2015;81:882-8.e1. doi: 10.1016/j.gie.2014.09.027.

60. Laine L, Jensen DM. Management of patients with ulcer bleeding. Am J Gastroenterol 2012;107:345-60; quiz 61. doi: 10.1038/ ajg.2011.480.

61. Barkun AN, Almadi M, Kuipers EJ, Laine L, Sung J, Tse F, et al. 
Management of Nonvariceal Upper Gastrointestinal Bleeding: Guideline Recommendations From the International Consensus Group. Ann Int Med 2019;171:805-22. doi: 10.7326/M19-1795.

62. Spiegel BMR, Vakil NB, Ofman JJ. Endoscopy for Acute Nonvariceal Upper Gastrointestinal Tract Hemorrhage: Is Sooner Better?: A Systematic Review. Arch Intern Med 2001;161:1393-404. doi: 10.1001/archinte.161.11.1393.

63. Tsoi KK, Ma TK, Sung JJ. Endoscopy for upper gastrointestinal bleeding: how urgent is it? Nat Rev Gastroenterol Hepatol 2009;6:463-9. doi: 10.1038/nrgastro.2009.108.

64. Taefi A, Cho WK, Nouraie M. Decreasing Trend of Upper Gastrointestinal Bleeding Mortality Risk Over Three Decades. Dig Dis Sci 2013;58:2940-8. doi: 10.1007/s10620-013-2765-Z.

65. Laine L, Yang H, Chang SC, Datto C. Trends for Incidence of Hospitalization and Death Due to GI Complications in the United States From 2001 to 200 9. Am J Gastroenterol 2012;107:11905; quiz 1196. doi: 10.1038/ajg.2012.168.

66. Loperfido S, Baldo V, Piovesana E, Bellina L, Rossi K, Groppo $\mathrm{M}$, et al. Changing trends in acute upper-GI bleeding: a population-based study. Gastrointest Endosc 2009;70:212-24. doi: 10.1016/j.gie.2008.10.051.

67. Lau JYW, Yu Y, Tang RSY, Chan HCH, Yip HC, Chan SM, et al. Timing of Endoscopy for Acute Upper Gastrointestinal Bleeding. New Engl J Med 2020;382:1299-308. doi: 10.1056/ NEJMoa1912484.

68. Stanley AJ, Laine L, Dalton HR, Ngu JH, Schultz M, Abazi R, et al. Comparison of risk scoring systems for patients presenting with upper gastrointestinal bleeding: international multicentre prospective study. BMJ 2017;356:i6432. doi: 10.1136/bmj.i6432. 